УДК 577.13:582.623.2

\title{
СЕЗОННАЯ ДИНАМИКА СОДЕРЖАНИЯ ДУБИЛЬНЫХ ВЕЩЕСТВ В ЛИСТЬЯХ И СОЦВЕТИЯХ НЕКОТОРЫХ ВИДОВ РОДА SALIX(SALICACEAE) ПРИ ИНТРОДУКЦИИ
}

\section{(C) А.А. Петрук}

\author{
Центральный сибирский ботанический сад, ул. Золотодолинская, 101, \\ Новосибирск, 630090 (Россия), e-mail: pet.a@mail.ru
}

Определена сезонная динамика содержания дубильных веществ в листьях и соцветиях Salix gracilistyla, S. phylicifolia, S. pentandra, S. pyrolifolia, S. rorida и S. schwerinii, интродуцированных в дендропарке Центрального сибирского ботанического сада СО РАН. В образцах листьев всех изученных особей количество дубильных веществ больше, чем в соцветиях. Максимумы содержания дубильных веществ в соцветиях приходятся на период полного цветения или начала плодоношения.

Ключевые слова: Salix, дубильные вещества, листья, соцветия.

\section{Введение}

Дубильные вещества (таннины) - сборное название для большого числа растительных полифенолов. Они широко распространены среди разных видов растений. Дубильные вещества обладают вяжущими, противовоспалительными, кровоостанавливающими и бактерицидными свойствами $[1,2]$. В этом плане интересны виды рода Salix L. (ивы), хорошо известные как дубильные растения, в коре которых содержится значительное количество дубильных веществ: от 2 до $8 \%[1,3]$. В научно-практической медицине используется в основном кора ив [1]. Представляет определенный интерес изучение содержания дубильных веществ в листьях и соцветиях, которые также могут быть источником лекарственных средств.

Цель настоящей работы - количественное определение дубильных веществ в листьях и соцветиях некоторых видов рода Salix, интродуцированных в Центральном сибирском ботаническом саду СО РАН.

\section{Экспериментальная часть}

Материалом для работы послужили листья и соцветия растений видов рода Salix: S. gracilistyla Miq., S. phylicifolia L., S. pentandra L., S. pyrolifolia Ledeb., S. rorida Laksch. и S. schwerinii E. Wolf, интродуцированных на территории дендропарка Центрального сибирского ботанического сада СО РАН (г. Новосибирск). Образцы были собраны в период с мая по сентябрь 2010 г. Всего было проанализировано 54 пробы.

Количественное определение дубильных веществ проводили путем окисления перманганатом калия в присутствии индигокармина по методу Левенталя-Нейбауера в модификации Курсанова [4]. На реакцию брали 5 мл вытяжки, добавляли 10 мл индигокармина и доводили водой до 300 мл с последующим титрованием 0,01 н $\mathrm{KMnO}_{4}$. Суммарное содержание дубильных веществ $(x$, в \% от массы воздушно-сухого сырья) определяли по формуле:

$$
x(\%)=\frac{(a-b) \times 4,157 \times V \times 100}{n \times V_{1} \times 1000},
$$

где $a$ - объем раствора $\mathrm{KMnO}_{4}$, израсходованного на титрование, мл; $b$ - объем раствора $\mathrm{KMnO}_{4}$, израсходованного на титрование в контрольном опыте, мл; 4,157 - количество дубильных веществ, соответствую-

Петрук Анастасия Андреевна - младший научный сотрудник лаборатории фитохимии, кандидат биологических наук, тел.: (383) 339-54-68, e-mail: pet.a@mail.ru щее 1 мл 0,01 н $\mathrm{KMnO}_{4}$, мг; $V$ - общий объем извлечения, мл; n - масса сырья, мг; $V_{1}$ - объем, взятый на титрование, мл. 


\section{Обсуждение результатов}

В динамике содержания дубильных веществ в листьях и соцветиях S. gracilistyla (рис. 1) можно отметить следующие особенности. Минимум веществ в листьях - 4,6\% - приходится на период активного роста листовой пластинки, в конце мая - начале июня. Постепенно содержание веществ возрастает до наибольшего значения в конце июня - 6,7\%, при этом размер листовых пластинок достигает максимальной величины, характерной для этого вида. В соцветиях максимум веществ - 2,9\% - приходится на конец мая, в период полного цветения, минимум - 2,1\% - на начало июня, в период начала плодоношения.

Для листьев S. phylicifolia (рис. 2) характерно наличие двух максимумов: 5,1\% дубильных веществ в середине июня, в фазу активного роста листьев; 7,1\% - в начале августа, в период, когда у растения листовые пластинки достигли своего наибольшего размера. Минимальное содержание дубильных веществ в листьях - 2,1\% - отмечено в начале сентября. Содержание веществ в соцветиях в конце цветения - начале плодоношения (начало июня) составляет $1,7 \%$.

Для листьев S. pentandra (рис. 3) характерно высокое содержание дубильных веществ (6,7\%) в листьях с мая, в период начала активного роста листовых пластинок, до середины июня, когда листовые пластинки достигают своего максимального размера, после чего количество веществ сводится к минимуму 4,6\%. В соцветиях максимум веществ зафиксирован в начале июня - 4,6\%, в период полного цветения. В фазу отцветания мужских соцветий содержание дубильных веществ снижается до минимума - 2,9\%.

Для листьев S. pyrolifolia (рис. 4) характерно наличие двух равноценных максимумов, которые составили 5,4\% в конце мая (начало роста листовых пластинок) и июня (листовые пластинки достигли своего максимального размера). Содержание веществ колебалось от 4,6 до 5,4\%. В соцветиях минимум веществ - 2,5\% зафиксирован в конце мая (начало цветения), максимум - 3,3\% - в начале июня (период полного цветения).

В динамике $S$. rorida (рис. 5) было выявлено, что наибольшее содержание дубильных веществ в листьях зафиксировано в мае $-3,3 \%$, в период начала роста листовой пластинки. В соцветиях количество их достигает максимума - 1,7\% - в фазу начала плодоношения. Как в листьях, так и в соцветиях минимум веществ отмечен в середине июня, в период конца плодоношения, когда листовые пластинки достигли своего максимального размера.

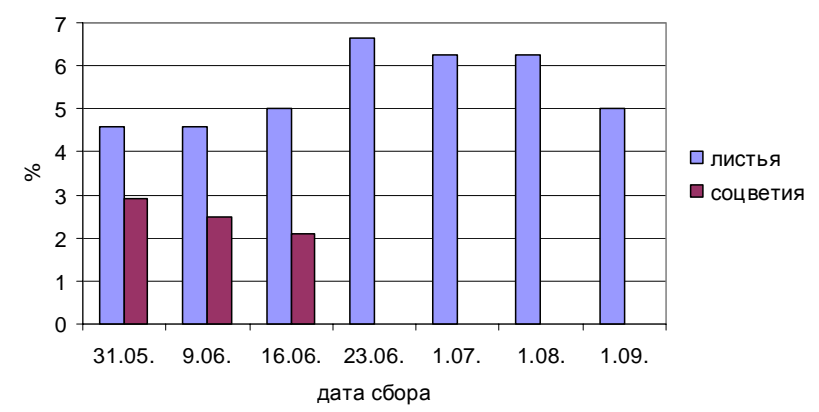

Рис. 1. Динамика содержания дубильных веществ в листьях S. gracilistyla

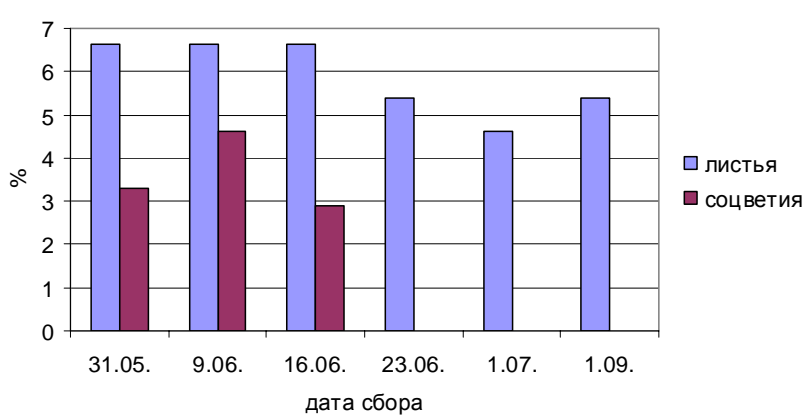

Рис. 3. Динамика содержания дубильных веществ в листьях $S$. pentandra

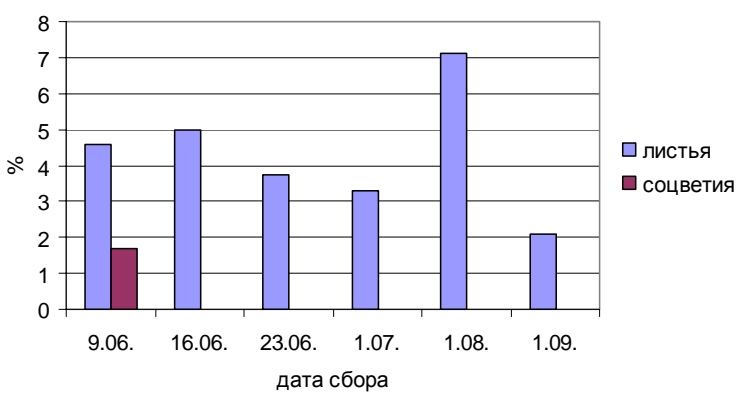

Рис. 2. Динамика содержания дубильных веществ в листьях S. phylicifolia

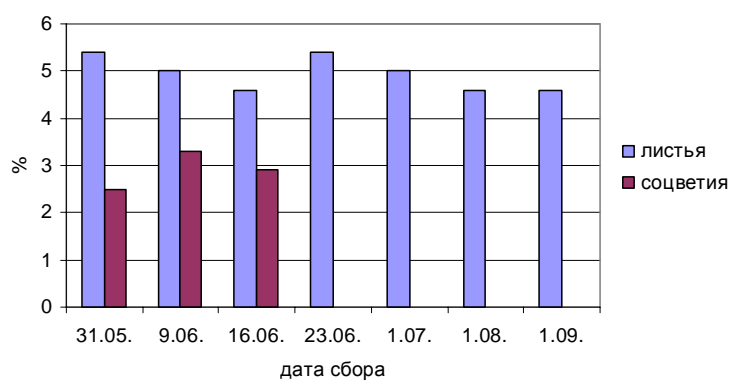

Рис. 4. Динамика содержания дубильных веществ в листьях S. pyrolifolia 
Для S. schwerinii (рис. 6) минимальное количество - 1,3\% - дубильных веществ в листьях приходится на конец мая и начало июля, в период активного роста листовой пластинки, наибольшее содержание 4,6\% - на конец июня и начало сентября, когда листовые пластинки достигли своего максимального размера. В соцветиях минимальное содержание веществ зафиксировано в конце мая, в период полного цветения, после чего количество их постепенно возрастает до 1,3\% в период начала плодоношения.

Полученные нами результаты по динамике содержания дубильных веществ в листьях и соцветиях согласуются с данными О.Э. Оразова [5] и Р.Ю. Фаррахова [6].

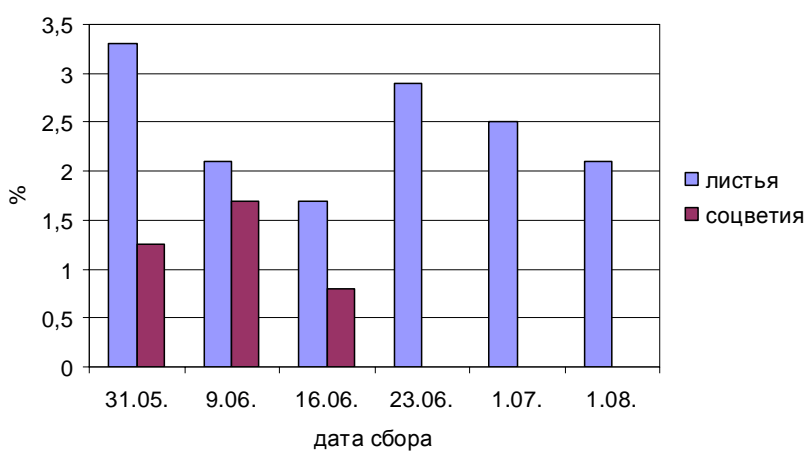

Рис. 5. Динамика содержания дубильных веществ в листьях $S$. rorida

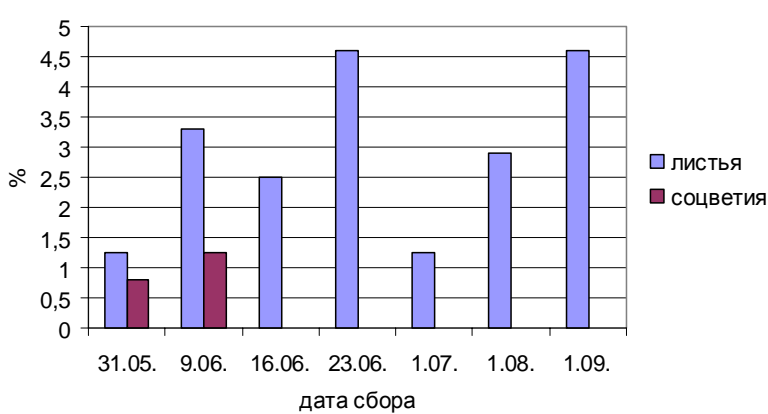

Рис. 6. Динамика содержания дубильных веществ в листьях $S$. schwerinii

\section{Вbыводы}

1. Наибольшее дубильных количество веществ в листьях характерно для S. phylicifolia - 7,1\%, наименьшее - для $S$. rorida - 3,3\%. Наибольшее количество веществ в соцветиях характерно для S. pentandra (мужские соцветия)- 4,2\%, наименьшее - 0,8\% - для S. rorida и $S$. schwerinii (женские экземпляры). В образцах листьев всех изученных особей количество дубильных веществ больше, чем в соцветиях.

2. Растения некоторых видов имеют одинаковые максимумы веществ в листьях, например, 6,6\% у S. gracilistyla и $S$. pentandra, минимум веществ - 4,6\% - отмечен у трех видов: S. gracilistyla, S. pyrolifolia и $S$. pentandra.

3. Общей тенденцией для изученных видов явилось то, что максимумы содержания дубильных веществ в соцветиях приходятся на период полного цветения или начала плодоношения. В период начала цветения или конца плодоношения зафиксированы минимальные значения по количеству дубильных веществ в соцветиях. Наибольшее содержание веществ в листьях отмечено в период начала роста листовых пластинок или в период, когда они достигают своего максимального размера.

\section{Список литературь}

1. Зузук Б.М., Куцик Р.В., Недоступ А.Т., Хоменец И.З., Пермяков В.В., Федущак Н.К. Ива белая Salix alba L. Аналитический обзор // Провизор. 2005. №15. С. 16-18.

2. Х Хелдт Г.В. Биохимия растений / пер. с англ. М., 2011. 471 с.

3. Неверова Л.А. Соотношение разнополых особей и содержание в них танидов у некоторых видов ивы в окрестностях Уральска // Растительные ресурсы. 1970. Вып. 2. С. 77-80.

4. Государственная фармокопея СССР. Общие методы анализа. М., 1987. Вып. 1. 335 с.

5. Оразов O.Э. Состав и накопление флавоноидов и танидов у женских и мужских клонов видов рода Salix L.: автореф. дис. ... канд. биол. наук. Уфа, 1998. 20 с.

6. Фаррахов Р.Ю. Комплексное использование водоохранно-защитных лесных насаждений (на примере видов рода Salix L.): автореф. дис. ... д-ра биол. наук. Тольятти, 2004. 19 с. 
Petruk A.A. SEASONAL DYNAMICS OF THE CONTENT OF TANNINS IN THE LEAVES AND INFLORESCENCES OF SOME SPECIES OF THE GENUS SALIX (SALICACEAE) IN THE INTRODUCTION

Central Siberian Botanical Garden, Zolotodolinskaya st., 101, Novosibirsk, 630090 (Russia), e-mail: pet.a@mail.ru

Seasonal dynamics of tannin content was determined in leaves and inflorescences of Salix gracilistyla, S. phylicifolia, S. pentandra, S. pyrolifolia, S. rorida, and S. schwerinii introduced in the arboretum of the Central Siberian Botanical Garden SB RAS. For all studied samples, tannin content was higher in leaves than in inflorescences. The maxima of tannin content in inflorescences were found during the periods of full bloom and early fruiting.

Keywords: Salix, tannins, leaves, inflorescence.

\section{References}

1. Zuzuk B.M., Kutsik R.V., Nedostup A.T., Khomenets I.Z., Permiakov V.V., Fedushchak N.K. Provizor, 2005, no. 15, pp. 16-18. (in Russ.).

2. Kheldt G.V. Biokhimiia rastenii. [Biochemistry of plants]. Moscow, 2011, 471 p. (in Russ.).

3. Neverova L.A. Rastitel'nye resursy, 1970, no. 2, pp. 77-80. (in Russ.).

4. Gosudarstvennaia farmokopeia SSSR. Obshchie metody analiza. [State Pharmacopeia of the USSR. Common methods of analysis.]. Moscow, 1987, no. 1. 335 p. (in Russ.).

5. Orazov O.E. Sostav i nakoplenie flavonoidov i tanidov u zhenskikh i muzhskikh klonov vidov roda Salix L.: avtoref. dis. ... kand. biol. nauk. [The composition and the accumulation of flavonoid and tannin female and male clones of the genus Salix L.: thesis abstract PhD]. Ufa, 1998, 20 p.

6. Farrakhov R.Iu. Kompleksnoe ispol'zovanie vodookhranno-zashchitnykh lesnykh nasazhdenii (na primere vidov roda Salix L.): avtoref. dis. ... d-ra biol. nauk. [Integrated use of Water-Protective forest plantations (for example, species of the genus Salix L.): thesis abstract Doctor of Biological Sciences]. Tol'iatti, 2004, 19 p. (in Russ.).

Received February 7, 2012 